\title{
Digital communication, social media, and Englishes
}

\author{
Jamie Shinhee Lee \\ University of Michigan-Dearborn, Michigan, USA \\ Correspondence
}

Jamie Shinhee Lee, College of Arts, Sciences, and Letters, University of Michigan-Dearborn, Michigan,USA.

Email: jamilee@umich.edu

Abstract

Scholarship in world Englishes has long been interested in the impact of digital media on the spread of English worldwide. This special issue on 'Digital media and world Englishes' examines how English(es) are positioned and used in relation to other languages in digital communication, what pragmatic functions English and other languages serve, and how various linguistic choices affect identity work in the context of digital communication. It is hoped that this special issue will make an important contribution to research in this field.

\section{1 | INTRODUCTION}

Digital communication has now become an integral part of routine interactions with others. Globalization is often mentioned as a facilitating factor in increasingly interconnected communication networks. As Seargeant and Tagg (2014, p. 2) point out, 'globalization changes our social and cultural relations; and communications technologies are a major driver behind such change.' Recent changes in communication technologies have affected language users rather significantly in terms of how they interact with others and how they form social bonds with others. Geographical, cultural, and linguistic boundaries are no longer as fixed and separating as before; sharing ethnic and cultural backgrounds is not necessarily a requirement for creating a sense of community. As far as language issues in digital communication are concerned, research generally reports two tendencies: 'the dominance of English as a lingua franca of transnational communication and the representation of linguistic diversity online' (Androutsopoulos, 2006, p. 428). This special issue primarily aims to explore: (1) how English(es) are positioned and used in relation to other languages in various domains of digital communication; (2) what pragmatic functions English and other languages serve; and (3) how various linguistic choices affect identity work. Digital communication has certainly impacted ways in which we construct, manage, and project identity. Authenticity and impersonation are often mentioned when it comes to online identity work (Page, 2014). As Wood and Smith (2005, p. 60) argue, "both what people say about themselves and how they behave with others contribute to the perception of personal identity online. The use of language is consequently of immense importance in cyberspace, for it is through the use of language that people construct their identities.'

This is the author manuscript accepted for publication and has undergone full peer review but has not been through the copyediting, typesetting, pagination and proofreading process, which may lead to differences between this version and the Version of Record. Please cite this article as doi:

10.1111/weng. 12447 .

This article is protected by copyright. All rights reserved. 
Sharing life and narratives online also inevitably invites a discussion of 'publically private' versus 'privately public' linguistic behavior, to borrow Lee's (2014) terms. Furthermore, Higgins' (1987) concepts of 'the actual self,' 'the ideal self,' and 'the ought self' are also useful in discussing how identities are performed and projected in digital communication. In analyzing user-generated online consumer reviews, Vásquez (2014, p. 86) observes that reviewer identities are 'invoked' through 'humour or cultural references.'

\section{2 | SCOPE OF SPECIAL ISSUE ON DIGITAL MEDIA AND WORLD ENGLISHES}

This special issue touches on several current and important sociolinguistic topics such as multimodality, translocality, heteroglossia, and intertextuality in digital communication, covering social network sites such as Facebook (Dovchin), Instagram (J. Lee), Twitter (Strelluf), and YouTube (Bhatia, Cutler, C. Lee, and Spilioti). It features papers representing heterogeneous venues in which English has different roles and status as well as presenting micro- and macro-sociolinguistic perspectives in varied domains of a society from education (Chik) to sports (J. Lee) to pop culture (C. Lee). I hope the special issue adequately addresses how languages co-exist or do their work collaboratively as well as competitively in digital communication. As globalization expands, English is often mentioned as a language replacing or threatening local languages.

Some of the questions we hope to answer in the issue are: (1) how multilinguals recruit various linguistic resources to construct, manage, and perform their online identities (such as homosexuals in Dovchin, sport fans in J. Lee, and a beauty guru in Bhatia); (2) what linguistic devices and multimodal resources are utilized to serve certain discourse purposes (for example, humor in Chik, C. Lee, and Spilioti; verbal aggression in J. Lee); (3) how translocality becomes relevant in digital communication (Dovchin); and (4) how intertexuality becomes significant in online communication (Cutler). Bhatia analyzes YouTube beauty tutorials by a British-Indian vlogger and discusses how she makes cultural references and uses code-switching to appeal to consumers who behave differently from socalled 'mainstream beauty standards.' By drawing upon Chang's (2014) notion of 'racialized beauty grammar,' Bhatia addresses how 'Indian-ness' is constructed and promoted in online beauty discourse by looking at beauty how-to vlogs and viewer comments. She notes that Kaushal, a highly influential YouTuber and an Indian beauty guru, shows what Bhatia terms 'interdiscursive identities' integrating both that of a super vlogger and of a diasporic Indian. The findings of Bhatia's research indicate that expert/disciplinary knowledge and selfcelebritification are commonly found in YouTube vlogs along with reciprocal endeavors to bond and construct a community with 'a collective identity' (Kavada, 2012), which values common ethnic and cultural heritage and traditions.

Cutler also discusses YouTube by examining 'instructional' videos, which is in a sense similar to Bhatia. However, the videos analyzed in Cutler's study are considered 'pseudo didactic,' to borrow her term. Her focus is on metapragmatic responses to YouTube videos about 'How to talk like a New Yorker' and written orthographic performances of a New York accent. She argues that YouTube commentaries provide rich sociolinguistic data revealing language attitudes and ideologies. Unlike previous research discussing negative attitudes toward the New York accent, most of the YouTube comments in Cutler's study show positive orientations to it. Findings of her study indicate that orthographic performances of the New York accent are executed through a few well-documented, arguably stereotypical, 
linguistic features representing the New York accent, including postvocalic $/ r /-\varnothing$, substituting < d > for 'th,' and the apical variant of -ING.' C. Lee's research recognizes Googlish 'as a valuable and playful linguistic resource' in digital communication (p. 12). Google Translates, one of the most popular online translation services, is viewed as helpful since it translates any text into over 100 languages. However, the accuracy of translation results is called into question as well. C. Lee focuses on Google Translate Sings (GTS hereafter), a series of music videos created by replacing original lyrics of popular songs with Google-translated English, and discusses how humor is generated by so-called (intentionally) mistranslated lyrics. Similar to J. Lee's Instagram users, YouTube video commenters in C. Lee's research also provide comments that have little to do with the original content. Based on viewer comments, C. Lee concludes that Googlish is perceived as lacking grammar and resulting in non-sensical 'English' sentences. C. Lee observes that 'the grammarlessness, foreignness, and incomprehensibility of Googlish are thus collaboratively constructed by the video creator, the video content, and the viewers' (p. 29). C. Lee argues that YouTube commenters serve dual roles as consumers of GTS and active producers of new Googlish contents (p. 33).

Spilioti examines Greek-Script English called engreek in memes and YouTube comments. By focusing on 'the weirding of English,' Spillioti discusses spelling manipulation in digital communication. She looks at memes featuring political figures and pop culture icons such as Alexis Tsipras and Angelina Jolie and discusses how humor is evoked through hybrid forms generated through manipulated orthography. She argues that trans-scripting achieves a visual exoticization of English that can be appreciated by bilingual, local, audiences' (p. 16). Her second set of data comes from YouTube videos of Greek singer Lefteris Pantazis's cover of Dan Wilson's rock ballad 'Breathless' and viewer comments. Spilioti observes that 'comments appear in Greek and English, at times in their conventional script and at times respelled as Greeklish (Roman-Alphabet Greek) or engreek (Greek-Alphabet English)' (p. 19). She reports on 'the prevalence of linguistic hybridity as a key resource for the production and circulation of humour on social media' (p. 27). Spilioti concludes that 'this form of weird English becomes a resource for representing local voices in highly mediatized political events' (emphasis in the original, p. 27). Dovchin examines the role and functions of the English language in the Mongolian gay community. Her analysis centers on Facebook posts by two gay men named Nek and Baatar, whose discursive practices and identity work show rather different tendencies. Temka's explicit projection of his homosexual identity is articulated through his comment on fashion and 'nakedness,' whereas Baatar's covert identity work is performed mainly through his use of 'linguistic homonormativities' (Leap, 2010) and affectionate and emotional lexical items, which Dovchin argues to be indicative of women's language in Mongolia. She concludes that Facebook serves as 'an alternative discursive space' -enabling Mongolian homosexual men to perform their gay identity and unreservedly express their desires through 'translingual English' (p. 25).

By reviewing Instagram posts about the 2018 Winter Olympics, J. Lee focuses on how us vs. them dichotomy and 'othering' practices are constructed discursively. Texts opposing the Korean team and the Chinese team reveal that nationalism, ethnocentrism, and essentialism are commonly summoned to strengthen their antagonistic narratives. Also, making references to seemingly unrelated events and ideas serves as a main rhetorical strategy to attack the opponent. Both verbal confrontation and conciliation are executed through linguistic mirroring, which closely mimics each other's lexical and syntactic features. Her

This article is protected by copyright. All rights reserved. 
research indicates that explicit defamation and stereotypical representation of the other are most frequently utilized by the participants in online conflict talk. Strelluf's paper has a quantitative research component and presents syntactic analysis based on a rather massive corpus. Investigating needs+PAST productions collected from tweets in 20 US cities, 17 UK cities, and 13 other cities, Strelluf observes that needs+PAST is a productive feature of Scotland, Belfast, Newcastle, and the US Midland. Recognizing the mysterious aspect of needs+PAST as 'temporally and spatially enduring but socially and psychologically invisible,' his research shows the usefulness of Twitter in studying low-frequency linguistic variables (p. 28). Relying on quantitative evidence, Strelluf concludes that 'a settler variety of English may leave an imprint of itself over several centuries' and notes 'the durability of regional dialect boundaries' (p. 1).

Chik investigates language learning social network sites and discusses how multilingual resources are recruited by English learners with diverse backgrounds especially to understand humorous discourses online. Using Deumert's (2014) notion of 'digital taverns,' Chik notes that Users of language learning social network sites present their ludic identities. Although the topics of Chik's research and J. Lee's study are different, both papers show that cultural stereotypes are often evoked by social network users. Chik's paper stands out in terms of research methodology. She adopts a longitudinal, 'auto-ethnographical' (Jones, 2007) approach to data collection. The researcher herself has been an active member of Duolingo, a popular online language learning platform, since 2013 and has taken courses and participated in discussion forums. She notes that teaching practitioners may not recognize humorous sentences on Duolingo as legitimate educational content but argues that discussion forums are facilitative in encouraging authentic interactions among users. Friedrich revisits some of the criticisms regarding Kachru's concentric circle model and suggests that the concept of digital Englishes should be added as 'a new layer' to capture its dynamic nature. She argues that 'it draws from every circle, and it is a space where varieties from each come together in negotiation. It has no geographical location, nor any physical, real or imagined boundaries. It is both realized in synchronicity and asynchrony' (p. 7). Fredrich proposes two revised models: digital Englishes added as a new layer and digital Englishes added as a wrap-around circle. She urges digital Englishes to be viewed not as 'a super-variety' on 'one or a group of identifiable English varieties' but 'as a pluralistic space where individual varieties are engaged in linguistic negotiation processes' (p. 9). She provides a general discussion of fan fiction, social media, and texting to argue that 'democratization' of writing and wider exposure to enhanced language contact situations online make these digital environments important sociolinguistic spheres requiring world Englishes scholars' attention. Friedrich's paper does not provide empirical findings or her own research details; its main goal seems to be to raise an awareness, among academics and non-academics alike, of the impact of digital communication on language change and possibly to consider sensible pedagogical tools for users who may face linguistic aggression online.

Most papers in this special issue touch on identity marking to a certain degree; some papers delve into the issue of identity more than others. For example, Dovchin's discussion centers around gay identity and J. Lee's paper discusses sport fan identity. Two papers in the issue focus on gender issues: feminine beauty in Bhatia and homosexual identity in Dovchin. These two papers also look at populations that have not been extensively researched in digital communication: diasporic India and Mongolia. Bhatia, Chik, and Cutler 
deal with some 'instructional' components; however, their main concerns are very different. Chik's paper has a truly education-related focus, discussing how ESL users tap into online sources in polishing their competence. YouTube videos teaching 'a New York accent' discussed in Cutler's paper, on the other hand, are not really for 'teaching' per se; rather they are meant to show folk notions and language ideologies about a particular regional accent. The nature of Indian beauty vlogging in Bhatia's paper is 'instructional' in terms of sharing helpful tips with viewers, but unlike Cutler and Chik, Bhatia does not discuss metalinguistic discourses about language. In terms of methodology and analysis, most papers in this issue are qualitative research oriented and present textual analysis with the exception of Strelluf, who shares some interesting quantitative results, albeit not extensive, based on a corpus analysis. It is also noteworthy that some under-researched areas of digital communication such as memes (Spilioti), online translation service (C. Lee), beauty tutorials (Bhatia), fan fiction (Friedrich), and sports (J. Lee) are discussed in the issue.

The journal World Englishes has previously published several articles related to the Internet and computer-mediated communication including Pandey (2003, the Ebonics debate on an electronic bulletin board); Dimova (2007, computer-related English loanwords on Macedonian business websites); Hardy and Friginal (2012, Filipino and American opinion columns and blogs); Troyer (2012, English in Thai online newspapers); Zhang (2015, multilingual creativity in Chinese microblogging); Ai and You (2015, syntactic features of English on an online discussion forum); Daud and Mclellan (2016, linguistic choices in Bruneian Facebook status updates); and Ong (2017, Singlish textese in multiparty chats). However, more contemporary social media platforms such as Facebook, Instagram, Twitter, and YouTube are hardly discussed as a main topic in the journal. Seargeant \& Tagg $(2014$, p. 2) argue that social media 'altered both communicative practices and patterns of social relations' and have 'a profound effect on the linguistic and communicative practices in which people engage, as well as the social groupings and networks they create.' It is my hope that the current special issue fills the research gap and addresses impacted social relations and communicative practices in specific enough ways so that it can serve as a springboard (1) to highlight social significance of these new (or not so new to many young language users) communicative channels through which identities are constructed, linguistic innovations are generated, and cultural and ethnic boundaries are crossed, and (2) to invite more substantial research and academic discussions.

\section{REFERENCES}

Ai, H., \& You, X. (2015). The grammatical features of English in a Chinese Internet discussion forum. World Englishes, 34, 211-230.

Androutsopoulos, J. (2006). Introduction: Sociolinguistics and computer-mediated communication. Journal of Sociolinguistics, 10, 419-438.

Chang, S. (2014).-In the eye of the beholder: Asian American YouTube beauty bloggers. In Thinking Gender Papers. eScholarship: University of California. 
Daud, N., \& McLellan, J. (2016). Gender and code choice in Bruneian Facebook status updates. World Englishes, 35, 571-586.

Deumert, A. (2014). The performance of a ludic self on social network(ing) sites. In P. Seargeant \& C. Tagg (Eds.), The language of social media: Identity and community on the Internet (pp. 23-45). London: Palgrave Macmillan.

Dimova, S. (2007). English, the Internet and computer terminology in Macedonia. World Englishes, 26, 373-387.

Hardy, J. A., \& Friginal, E. (2012). Filipino and American online communication and linguistic variation. World Englishes, 31, 143-161.

Higgins, E. T. (1987). Self-discrepancy: A theory relating self and affect. Psychological Review, 94, 319-340.

Jones, S. H. (2007). Autoethnography. In The Blackwell encyclopedia of sociology (pp. 1-2). Retrieved from https://doi.org/10.1002/9781405165518.wbeosa082

Kavada, A. (2012). Engagement, bonding, and identity across multiple platforms: Avaaz on Facebook, YouTube, and MySpace. MedieKultur: Journal of Media and Communication Research, 52, 28-48.

Leap, W. L. (2010). Globalization and gay language. In N. Coupland (Ed.), The Handbook of language and globalization (pp. 555-574). Chichester: Wiley-Blackwell.

Lee, C. (2014). Language choice and self-presentation in social media: The case of university students in Hong Kong. In P. Seargeant \& C. Tagg (Eds.), The language of social media (pp. 91-111). New York: Palgrave Macmillan.

Ong. K. K.W. (2017). Textese and Singlish in multiparty chats. World Englishes, 36(4), 611630

Page, R. (2014). Hoaxes, hacking and humour: Analysing impersonated identity on social network sites. In P. Seargeant \& C. Tagg (Eds.), The language of social media (pp. 46-64). New York: Palgrave Macmillan.

Pandey, A. (2003). Linguistic power in virtual communities: The Ebonics debate on the Internet. World Englishes, 19, 21-38.

Seargeant, P., \& Tagg, C. (2014). Introduction: The language of social media. In P. Seargeant \& C. Tagg (Eds.), The language of social media (pp. 1-21). New York: Palgrave Macmillan.

Troyer, R. A. (2012). English in the Thai linguistic netscape. World Englishes, 31, 93-112.

Vásquez, C. (2014). 'Usually not one to complain but ...': constructing identities in usergenerated online reviews. In P. Seargeant \& C. Tagg (Eds.), The language of social media (pp. 65-90). New York: Palgrave Macmillan.

Wood, A. F., \& Smith, M. J. (2005). Online communication: Linking technology, identity, culture. Mahwah, NJ: Erlbaum.

Zhang, W. (2015). Multilingual creativity on China's Internet. World Englishes, 34, 231-246.

This article is protected by copyright. All rights reserved. 